\title{
VOYRIA APHYLLA (GENTIANACEAE), LA PRIMERA EUDICOTILEDÓNEA MICOHETERÓTROFA REGISTRADA PARA LA FLORA ARGENTINA
}

\author{
Voyria aphylla (Gentianaceae) the first mycoheterotrophic Eudicot recorded for \\ the Argentinian flora
}

FABIÁN E. GATTI'10 \& HÉCTOR A. KELLER²(1)

\begin{abstract}
Resumen: Sobre la base de dos muestras recolectadas en Misiones, se documenta por primera vez para el territorio argentino la presencia de una especie micoheterótrofa aclorofilada, Voyria aphylla (Jacq.) Pers. (Gentianaceae). La especie es ilustrada mediante fotografías de especímenes y se provee información ecológica sobre los lugares donde crece esta planta.
\end{abstract}

Palabras clave: Bañados, Misiones, plantas aclorofiladas.

Summary: Based on two samples collected in Misiones, the presence of a species of mycotrophic achlorophyllous plant, Voyria aphylla (Gentianaceae), is documented for the first time in Argentina. The species is illustrated with photographs, and ecological information on the places where this plant grows is provided.

Key words: Aclorophyllous plants, marshes, Misiones province.

\section{Introducción}

En el Neotrópico crecen especies de plantas aclorofiladas parásitas de hongos pertenecientes a seis familias botánicas: Burmanniaceae, Corsiaceae, Gentianaceae, Orchidaceae, Pyrolaceae y Triuridaceae (Maas et al., 1986). En la Argentina se han mencionado hasta el presente cuatro de ellas, debido a que las Pyrolaceae no poseen representantes en nuestra flora y para las Gentianaceae sólo se han documentado especies autótrofas dentro del territorio nacional (Krauczuk et al., 2013). El hallazgo de ejemplares de Voyria aphylla (Gentianaceae) en áreas palustres del departamento Iguazú, Misiones, permite elevar a cinco las familias de plantas micoheterótrofas presentes en nuestro país, así como también documentar la primera especie Eudicotiledónea parásita de hongos presente en la Argentina.

\section{Resultados}

Voyria aphylla (Jacq.) Pers., Synops. P1. 1: 284. 1805 (as "Vohiria"). Fig. 1.

Sinonimia e iconografia en Maas et al., 1986. Fl. Neotrop. Monograph 42: 133-136. Fig. 60. 1986.

Hierba aclorofilada $15-30 \mathrm{~cm}$ alt. Tallos usualmente simples, raramente bifurcados en la base, teretes, anaranjados, amarillos o blanquecinos. Hojas escuamiformes, estrechamente ovadas a estrechamente triangulares, 4-8 × 0,9-1 mm. Inflorescencias 1(2-) flora. Brácteas y bractéolas similares a las hojas superiores, pero más pequeñas, 1,5-2 $\times$ 1,4-1,5 mm. Flores pentámeras, anaranjadas. Cáliz campanulado a cilíndrico, tubo 3-6 $\mathrm{mm}$ long., dientes triangulares a anchamente triangulares, 1-2 × 1-1,5 mm, ápice agudo a acuminado, escamas presentes. Corola

${ }^{1}$ Centro de Investigaciones Ecológicas Subtropicales, Parque Nacional Iguazú, Misiones.

${ }^{2}$ Instituto de Botánica del Nordeste-CONICET, Casilla de Correo 209, 3400-Corrientes, Argentina. E-mail: ibone@, agr.unne.edu.ar 


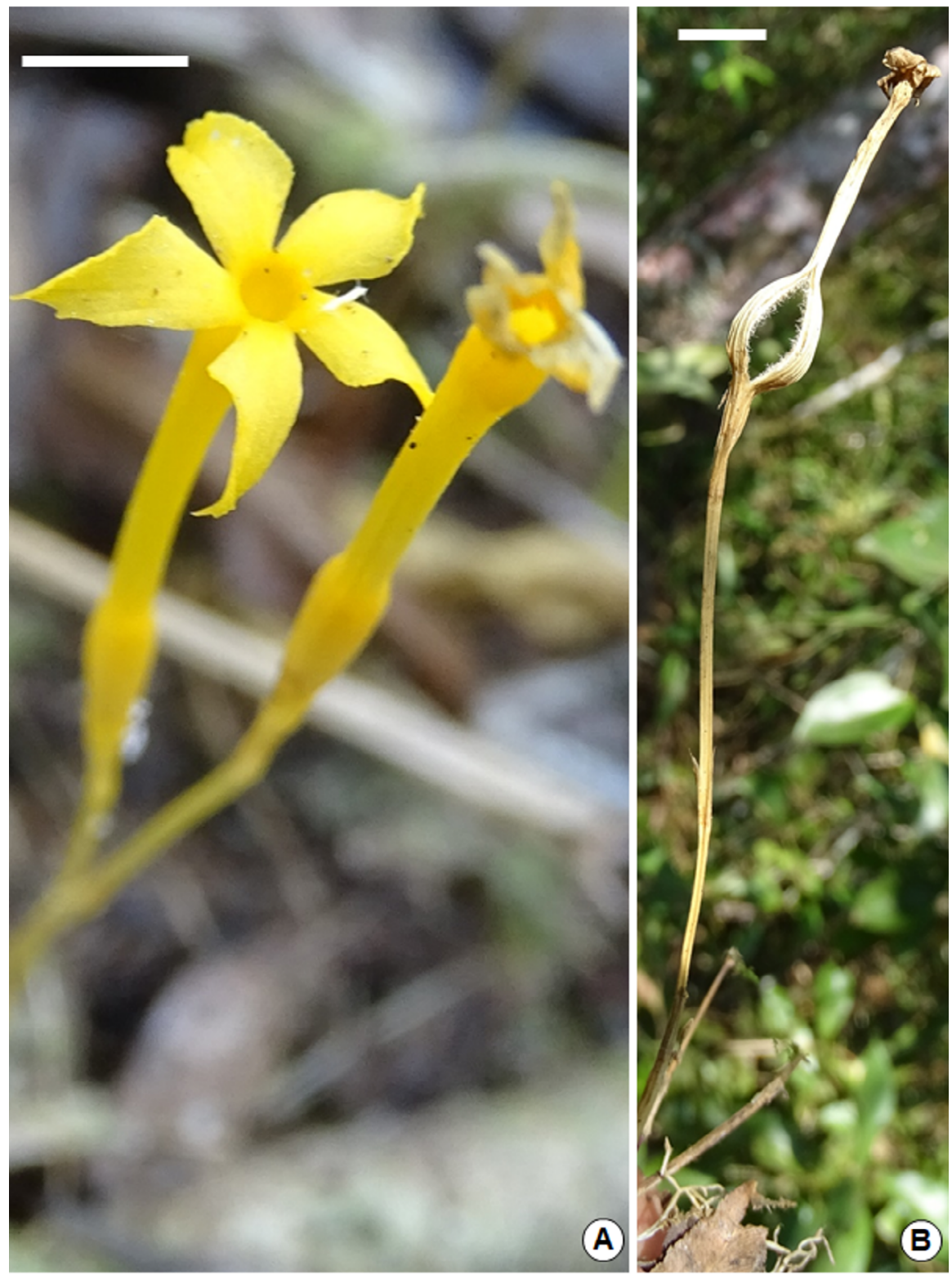

Fig. 1. Voyria aphylla (Gentianaceae). A: flor. B: fruto (A, B, Keller \& Rojas 13635) (Fotos: H. A. Keller). Escalas. A: $9 \mathrm{~mm}$. B: $3 \mathrm{~mm}$.

Fig. 1. Voyria aphylla (Gentianaceae). A: flower. B: fruit.(A, B, Keller \& Rojas 13635) (Photos: H. A. Keller). Scales. A: $9 \mathrm{~mm}$. B: $3 \mathrm{~mm}$.

hipocraterimorfa, tubo cilíndrico, 20-50 $\mathrm{mm}$ long., dilatado en la base, lóbulos estrechamente ovados a estrechamente obovados, 4-15 × 1-5 $\mathrm{mm}$, a veces minutamente piloso. Estambres insertos 3-5 mm debajo de la garganta, anteras subsésiles, 0,3-0,8 $\mathrm{mm}$ long., dorsifijas, tecas con ápice redondeado y base estrecha. Ovario fusiforme, $5-8 \times 1 \mathrm{~mm}$, subsésil a estipitado. Estilo 10-30 mm long., estigma capitadopeltado, 5-lobado. Cápsula septicida fusiforme, $8-10 \times 1,5-2,5 \mathrm{~mm}$. Semillas filiformes a fusiformes, $0,6-0,9 \times 0,04-0,06 \mathrm{~mm}$. 
Material examinado. ARGENTINA. Misiones: Dep. Iguazú, Parque Nacional Iguazú, 2539'49,3'S, 5430'22,3'”W, 10-IV-2019, Gatti 276 (CTES); Pto. Bossetti, 2548'53,8'S, 543'09,8'W, 06-IX-2017, Keller \& Rojas 13635 (CTES).

Distribución y fenología: Se distribuye a lo largo del Neotrópico desde México hasta la Argentina (Maas et al., 1986). En la Argentina su área de ocurrencia conocida se limita al nordeste de Misiones, departamento Iguazú. En base a observaciones de campo, se estima que florece y fructifica todo el año.

Observaciones ecológicas: Crece desde el nivel del mar hasta los 1800 m s.n.m., en varios tipos de bosques, selvas lluviosas, bosques pantanosos, sabanas arboladas, caatinga amazónica. También en restingas y sabanas, inclusive en arenas blancas crece en mantillo o troncos de árboles caídos (Maas et al., 1986). En la Argentina (Misiones) fue hallada en dos áreas pantanosas bajo dosel arbóreo principalmente de Copaifera langsdorfii Desf. (Fabaceae). Los sectores con mayor cobertura del sotobosque se constituyen de helechos y latifoliadas, mientras que en los espacios más abiertos predominan gramíneas y ciperáceas. Voyria aphylla se oculta bajo el denso pastizal, donde comparte su hábitat con briófitas y diversas angiospermas de tamaño reducido, incluyendo otras micoheterótrofas como Apteria aphylla (Nutt.) Barnhart ex Small (Burmanniaceae).

Observaciones taxonómicas: En Argentina crecen 45 especies de la familia Gentianaceae, 41 nativas y 5 adventicias. Las especies nativas se distribuyen en 11 géneros. Voyria aphylla es la primera especie aclorofilada de la familia que se documenta para el país.

Con la presente adición la flora de nuestro país incluye a ocho especies de plantas micoheterótrofas, las cuales se pueden diferenciar mediante la siguiente clave.

\section{Clave para diferenciar las especies de plantas micoheterótrofas presentes en Argentina}

A. Hojas opuestas, flores pentámeras. Voyria aphylla (Jacq.) Pers.

$\mathrm{A}^{\prime}$. Hojas alternas flores trímeras.

B. Flores hipóginas, dialicarpelares. Peltophyllum luteum Gardn. (Triuridacee)

$\mathrm{B}^{\prime}$. Flores epíginas, gamocarpelares.

C. Estambres fértiles 1, polen en polinias. Wullschaegelia aphylla (Sw.) Rchb. f. (Orchidaceae) $\mathrm{C}^{\prime}$. Estambres fértiles 3 o 6 .

D. Flores cigomorfas, estambres 6 , libres. Arachnitis uniflora Phil. (Corsiaceae)

D'. Flores actinomorfas, estambres 3, soldados al perigonio.

E. Ovario trilocular.

F. Flores trígonas. Conectivo de las anteras con dos apéndices carnosos. Burmannia capitata (Michx.) Mart. (Burmanniaceae)

F.' Flores aladas. Conectivo de las anteras triangular.

Burmannia flava Mart. (Burmanniaceae)

$E^{\prime}$. Ovario unilocular.

G. Parte superior del tubo floral caduca.

Gymnosiphon divaricatum (Benth.) Benth. \& Hook. f. (Burmanniaceae)

$\mathrm{G}^{\prime}$. Parte superior del tubo floral persistente. Apteria aphylla (Nutt.) Barnhart ex Small (Burmanniaceae) 


\section{Bibliografía}

KRAUCZUK, E. R., M. E. RODRÍGUEZ,A. E. CARDOZO $\&$ H. A. KELLER. 2013. Nuevos registros de plantas micoheterótrofas aclorofiladas para la provincia de
Corrientes, Argentina. Bonplandia 22: 131-135.

MAAS, P. J. M., H. MAAS-VAN DE KAMER, J. VAN BENTHEM, H. C. M. SNELDERS \& T. RÜBSAMEN. 1986. Saprophytic Pro Parte. Flora Neotropica Monographs 40, 41, 42: 1-189. 